\title{
Nulidad del acto jurídico administrativo
}

Pedro G. Morales Corrales

\section{El Acto Jurídico en el Código Civil}

De acuerdo con los Doctores Pedro Patrón Faura y Pedro Patrón Bedoya, para analizar el acto jurídico administrativo es necesario recurrir al acto jurídico regulado por el Código Civil, con el objeto de conocer su contenido y establecer si éste es aplicable íntegramente al Derecho Administrativo o si existe algún tipo de incompatibilidad que determine la existencia de características especiales de este acto en el campo del Derecho Administrativo'. (Art. IX del Título Preliminar del Código Civil).

\section{Concepto de acto jurídico}

El Código Civil en su artículo $140^{\circ}$ define el acto jurídico como «la manifestación de voluntad destinada a crear, regular, modificar o extinguir relaciones jurídicas». Para su validez se requiere: agente capaz, objeto física y jurídicamente posible, fin lícito, observación de la forma prescrita bajo sanción de nulidad.

\section{Nulidad del acto jurídico}

El mismo código sustantivo, en su artículo $219^{\circ}$ establece las causales

Patrón Faura, Pedro y Patrón Bedoya, Pedro, Derecho Administrativo y Administración Pública en el Perú, Quinta edición ampliada y actualizada, Editora GRIJLEY, Lima, Perú, 1996, p. 295. 
de nulidad del acto jurídico y determina que éste es nulo: cuando falta la manifestación de voluntad del agente; cuando se haya practicado por persona absolutamente incapaz, salvo lo dispuesto en el artículo $1358^{\circ 2}$; cuando su objeto es física o jurídicamente imposibbe o cuando sea indeterminable; cuando su fin sea ilícito; cuando adolezca de simulación absoluta; cuando no revista la forma prescrita bajo sanción de nulidad; cuando la ley lo declara nulo; y, en el caso del artículo V del Título Preliminar ${ }^{3}$, salvo que la ley establezca sanción diversa.

Marcial Rubio Correa ${ }^{4}$ se adhiere al concepto de Giuseppe Stolfi quien considera que "Es nulo el negocio al que le falte un requisito esencial, o bien sea contrario al orden público o a las buenas costumbres, o bien infrinja una norma imperativa. ${ }^{5}$

Stolfi, mencionado por Rubio sostiene que existen dos tipos de nulidades en la legislación positiva: la expresa o textual, o la tácita o virtual ${ }^{6}$.

La primera consta expresamente en el texto de las normas jurídicas, es decir que la norma específicamente sanciona con la nulidad la inobservancia de alguna condición o forma. Por ejemplo artículo $156^{\circ}$ del Código Civil cuando establece que «Para disponer de la propiedad del representado o gravar sus bienes, se requiere que el encargo conste en forma indubitable y por escritura pública, bajo sanción de nulidad.»

La nulidad tácita o virtual, siempre siguiendo a Stolfi, citado por Rubio, es aquella que no consta expresamente en el texto de la norma, pero que puede desprenderse fácilmente de él, a partir de la aplicación de las reglas de interpretación o del argumento a contrario, lo cual significa que si como consecuencia de la aplicación de tales métodos se advierte que el acto entra en conflicto con disposiciones gales entonces dicho acto sería nulo.

Igualmente, citando a Georges Ripert y Jean Boulanger, Rubio manifiesta que la nulidad tácita o virtual existe ... solamente porque no han sido respetadas las prescripciones legales en la conclusión del contrato. La Ley no da la lista de los casos de nulidad ... . El método del legislador es

2 Código Civil, Art. 1358: «Los incapaces no privados de discernimiento pueden celebrar contratos relacionados con las necesidades ordinarias de su vida diaria».

${ }^{3} \quad$ Código Civil, Art. V del Título Preliminar, «Es nulo el acto jurídico contrario a las leyes que interesan al orden público o a las buenas costumbres».

4 Rubio Corrti, Marcial, Nulidad y Anulabilidad.- La Invalides del Acto Juridico, Biblioteca para Leer el Código Civil, Volumen IX, PUC, Fondo Editorial 1989, p. 21.

5 Stolfi, Giuseppe, Teoría del Negocio Jurídico, Madrid, Editorial Revista de Derecho Privado, 1959, p. 80.

Op. cit. p. 21. 
diferente: fija las condiciones de validez del acto o contrato. Se incurre en nulidad cuando falta una de estas condiciones.» ${ }^{7}$ Así, en nuestro Código Civil por ejemplo, el artículo V del Título Preliminar encuadraría en el caso de una nulidad tácita o virtual (véase llamada 3 ), en cuyo caso habrá que elucidar si determinado acto efectivamente contraría el orden público o agravia a las buenas costumbres. De llegarse a dicha conclusión entonces se considerará que el acto es nulo.

Sin embargo, hay que advertir que el artículo $219^{\circ}$ del Código Civil establece taxativamente los casos en que el acto jurídico es considerado nulo. Ello significa que aquellos no contemplados en dicha norma, no serán considerados nulos para el ámbito civil o privado.

Si esto es así, cuando el inciso 8 de dicho artículo establece que el acto jurídico es nulo en el caso del artículo $\mathrm{V}$ del Título Preliminar, dicho artículo sólo se refiere a las leyes que interesan al orden público o a las buenas costumbres y no a la totalidad de las leyes, por lo cual, la teoría de la nulidad virtual, en la extensión que le estaría dando Marcial Rubio, no necesariamente se encuadraría dentro de los alcances del artículo 219 del Código Civil. Por el contrario y como lo veremos más adelante, sí lo estaría respecto de la nulidad del acto administrativo.

Una conclusión importante a la que llega Rubio es que «la falta de los elementos esenciales del acto jurídico no es causal de inexistencia, sino específicamente de nulidad, a tenor de diversos incisos del artículo $219^{\circ}$. Por consiguiente, hay que señalar que nuestro Código no opta por reconocer la teoría de la inexistencia del acto: entre nosotros sólo existen la nulidad y la anulabilidad. Los casos que en otros sistemas se consideran de inexistencia, entre nosotros son de nulidad $»^{8}$.

Otra conclusión importante a la que llega Rubio es que «El acto nulo debe ser considerado como existente (pues sólo puede ser calificada alguna entidad existente), pero resulta privado de efectos»".

\section{Efectos de la nulidad}

Fernando Vidal Ramírez, autor de la Exposición de Motivos del Libro II -Acto Jurídico- del Código Civil de 1984, refiriéndose a los actos nulos considerados en el artículo $219^{\circ}$ del Código Civil, expresa que

Op. it. p. 21

Op. cit. p. 25.

Op. cit. p. 25. 
«El acto nulo lo es de pleno derecho, lo que significa que no requiere de una sentencia judicial que así lo declare. Como característica de la nulidad ipso jure es que el acto sea jurídicamente inexistente, o sea, que no genera efectos...». Continúa diciendo: «La nulidad absoluta hace, pues, que el acto no produzca los efectos queridos por las partes... $\rangle^{10}$

Sobre este mismo tema, Rubio citando a Stolfi sostiene que en cuanto a las partes puede decirse que ninguna de ellas puede pretender cosa alguna de la otra basándose en el acto inválido, porque de otro modo el negocio produciría el efecto que le es propio. Si el negocio ha sido cumplido las cosas deben reponerse en su estado anterior, como si el acto no se hubiese realizado ya que no tuvo ni puede tener eficacia alguna. Concluye mencionando que si esto ocurre en las relaciones bilaterales o plurilaterales, también sucede en un acto unilateral: No produce efectos. ${ }^{11}$

A su vez, Francesco Messineo, sostiene lo siguiente: «La nulidad obra de pleno derecho, es decir, actúa sin necesidad de ser declarada y el interesado no tiene la carga de una iniciativa para hacerla pronunciar; y la eventual acción es siempre de declaración de certeza (negativa) para todos los posibles efectos futuros, aunque falte un interés actual del sujeto.» ${ }^{12}$

Una conclusión importante consiste entonces en que, la Exposición de Motivos del actual Código Civil identifica al «acto jurídico nulo», con el «acto jurídico nulo de pleno derecho».

Anteriormente este tema no resultaba de una claridad absoluta por to que llevó a diferenciar entre una suerte de acto jurídico nulo comín que requería de una declaración judicial previa, del acto jurídico nulo de pleno derecho o ipso jure que no necesitaba de ninguna declaración judicial para oponerse a un tercero.

Tal vez esta última distinción en alguna forma resultaba superflua o poco práctica, ya que a decir de los Mazeaud, citado por Rubio ${ }^{13}$, bastaba que la contraparte no acepte la alegada nulidad ipso jure o de pleno derecho para que se tuviera que recurrir a los tribunales a fin de que ésta sea declarada.

11) Código Civil: Exposición de Motivos y Comentarios.- Comisión Encargada del Estudio y Revisión del Código Civil.- Compiladora: Delia Rhvorforo dr Marsano, Lima, Perú 1985, Tomo IV, p. 332.

11 Op. cit.p. 26.

12 Messinto, Francisco, Doctrina General del Contrato, Tomo II, Ediciones Jurídicas Europa - América, Buenos Aires, p. 273.

13 Op. cit. p. 27 
En efecto, el artículo $220^{\circ}$ del Código Civil establece que la nulidad a que se refiere el artículo $219^{\circ}$ puede ser alegada por quienes tengan interés, lo que significa que si la contraparte no reconoce la existencia de la nulidad entonces existirá interés porque ésta sea declarada. El mismo artículo también prevé que la declaración de nulidad pueda ser demandada por el Ministerio Público y que, asimismo, puede ser declarada de oficio por el Juez cuando resulte manifiesta (nulidad expresa o textual).

En este mismo sentido se pronuncia Fernando Vidal cuando manifiesta que: «... Sólo si una de las partes, o ambas, pretende su validez, corresponderá al Juez declarar la nulidad absoluta sin que la sentencia tenga un carácter constitutivo sino declarativo. $\rangle^{14}$

En consecuencia, los actos nulos a que se refiere el artículo $219^{\circ} \mathrm{del}$ Código Civil, lo son ipso jure o de pleno derecho sin necesidad de que se consigne este calificativo; no surte ningún efecto jurídico y es oponible a terceros. Además no puede convalidarse mediante su confirmación. Sin embargo, de requerirse, se puede recurrir al órgano jurisdiccional para que declare la existencia de dicha nulidad, que nunca surtió efectos y que resulta insubsanable.

\section{Prescripción de la acción de nulidad}

El inciso $1^{\circ}$ del artículo $2001^{\circ}$ del Código Civil, establece que prescribe a los diez años la acción de nulidad del acto jurídico; lo cual no implica que vencido el plazo de prescripción la nulidad quede revertida o subsanada, sino que por razones de seguridad jurídica pueda oponerse a quien la alega, la excepción de prescripción, por lo que, si bien el acto jurídico nulo continúa siéndolo, el interesado perdió la acción para que sea declarada (CC Art. 1989²), aún cuando el Código permite la renuncia expresa o tácita de la prescripción ya ganada (Art. 1991ํ) y determina además que el juez no puede invocarla de oficio, lo que supone un pedido expreso de parte (CC artículo 1992으. En otros términos, teóricamente, aun cumplido el plazo de prescripción, a quien le interese alegar la nulidad de un acto jurídico podría hacerlo incluso judicialmente y de ser fundada, la demanda prosperaría si es que el demandado no le opone expresamente la excepción de prescripción. 


\section{Anulabilidad del acto jurídico}

El Código Civil peruano diferencia entre el acto jurídico nulo y el anulable. El artículo $221^{\circ}$ considera que el acto jurídico es anulable por incapacidad relativa del agente; por vicio resultante de error, dolo, violencia o intimidación; por simulación, cuando el acto real que lo contiene perjudica el derecho del tercero; y, cuando la ley lo declare anulable.

Rubio, citando a Manuel Albaladejo manifiesta que «el negocio anulable (también llamado impugnable) es plenamente eficaz, pero, por haberse celebrado con determinados defectos, está amenazado de destrucción, con la que se borrarían retroactivamente los efectos producidos. Se trata de un negocio provisionalmente válido (no hay validez actual) que, por tanto, modifica la situación jurídica preexistente...». ${ }^{15}$

Fernando Vidal Ramírez, manifiesta que «mientras que el acto anulable no sea anulado se le considera válido y produce todos sus efectos, que son los queridos por las partes, tanto para ellas como para los terceros. Por ello ..., es que su nulidad requiere necesariamente de una sentencia judicial que lo declare nulo desde su celebración, por lo que la sentencia, pese a su efecto retroactivo es de carácter constitutivo y no declarativo». ${ }^{16}$

En efecto, el artículo $222^{\circ}$ del Código Civil establece que «el acto jurídico anulable es nulo desde su celebración, por efecto de la sentencia que lo declare. Esta nulidad se pronunciará a petición de parte y no puede ser alegada por otras personas que aquellas en cuyo beneficio la establece la ley.»

En consecuencia, otra característica del acto jurídico anulable es que su nulidad, a diferencia del acto nulo manifiesto, no puede ser declarada de oficio sino a petición de parte. También, que salvo el derecho de terceros, puede ser confirmado por la parte a quien corresponda la acción de anulación, mediante instrumento que contenga la mención del acto que se quiere confirmar, la causal de anulabilidad y la manifestación expresa de confirmarlo. (CC Art. 230 ${ }^{\circ}$ ). Igualmente queda confirmado el acto anulable si la parte a quien correspondía la acción de anulación, conociendo la causal, lo hubiese ejecutado en forma total o parcial, o si existen hechos que inequívocamente pongan de manifiesto la intención de renunciar a la acción de anulabilidad. (CC Art. $231^{\circ}$ ), lo que resulta en todos los casos mencionados imposible con el acto jurídico nulo. 


\section{Acto jurídico administrativo}

Conocidos los alcances del acto jurídico regulado por el Código Civil, sus causales de nulidad y anulabilidad y los alcances de estos dos últimos conceptos, nos toca analizar a continuación si el acto jurídico administrativo, tal como se encuentra regulado por el Texto Único Ordenado (TUO) de la Ley de Normas Generales de Procedimientos Administrativos, aprobado por Decreto Supremo № 02-94-JUS de 28 de enero de 1994, tiene contenidos y efectos iguales o similares que los regulados por el Código Civil.

El TUO alcanza a todos los actos de la administración pública, entendiéndose por tal, a los ministerios, instituciones y organismos públicos descentralizados, gobiernos regionales, gobiernos locales, los organismos constitucionalmente autónomos y las empresas u otras entidades públicas y privadas que prestan servicios públicos, incluidas las universidades públicas y privadas. Adviértase lo irrazonable que resulta otorgar a los actos que realizan las universidades privadas y las empresas privadas que prestan servicios públicos, la categoría de actos administrativos.

El Decreto Legislativo № 817 -Ley del Régimen Previsional a cargo del Estado-, amplía el ámbito a las empresas que pertenecen a la actividad empresarial del Estado, sin distinción de que presten o no servicios públicos, en el sentido de que todos los actos relacionados a los regímenes pensionarios a cargo del Estado que puedan dictar estas empresas constituyen «actos administrativos de Derecho Público" (Art. $\left.3^{\circ}\right)$.

El contenido del artículo $113^{\circ}$ del TUO, ubicado dentro de las Disposiciones Finales, cuando realmente debió serlo dentro del Título II del TUO -Actuación Administrativa- Capítulo II -De los Actos Administrativos-, define a los actos administrativos como «... las decisiones de las autoridades u órganos de la Administración Pública que, en ejercicio de sus propias funciones, resuelven sobre intereses, obligaciones o derecho de las entidades administrativas, o de los particulares respecto de ellas.».

Para los autores Pedro Patrón Faura y Pedro Patrón Bedoya surge el acto administrativo cuando el acto jurídico es realizado por una entidad estatal o un funcionario público, definiendo el acto administrativo, como «toda manifestación de voluntad o decisión, general o especial, de una entidad estatal, de un funcionario o autoridad competente, en ejercicio de sus funciones, que producen efectos de derecho respecto al Estado o a particulares en el ámbito de su autoridad y responsa- 
bilidad, susceptibles de impugnación administrativa o judicial según el caso». ${ }^{17}$

Los autores mencionados concluyen que, para que el acto jurídico sea administrativo es necesario que lo realice la Administración Pública, a través de sus funcionarios investidos de autoridad.

En consecuencia, el elemento determinante que diferencia actos administrativos de actos jurídicos de derecho privado, es que el acto administrativo constituye el ejercicio de la potestad pública, lo que no sucede con el acto privado. ${ }^{18}$

El TUO no ha determinado expresamente cuáles son los requisitos de validez del acto administrativo. Sin embargo, el artículo $43^{\circ}$ del TUO, establece las causales de nulidad de los actos administrativos. De tal disposición puede inferirse, según razonamiento interpretativo a contrario, los requisitos de validez de los mismos que serían órgano competente, sujeción a la Constitución y las leyes, posibilidad jurídica; y, observancia de las normas esenciales del procedimiento y de la forma prescrita por la ley.

Sin duda, estos requisitos que consideramos implícitos en la ley son similares con los que doctrinariamente enumera y explica Humberto Núñez Borja ${ }^{19}$. Este autor abunda en detalles acerca del contenido de cada uno de los requisitos de validez de los actos administrativos ${ }^{2(1)}$ y que de manera sucinta son los siguientes:

a) Autoridad competente. El acto debe emanar de un administrador calificado para tal acto, no de cualquier funcionario. Por ello, todo funcionario público debe actuar dentro del área de acción que las leyes o reglamentos le hubiesen establecido. La competencia requiere texto claro e inequívoco de la normatividad vigente. La competencia entraña, por lo demás, el cumplimiento de una obligación ineludible.

b) Formalidades legales o reglamentarias. El acto administrativo debe observar ciertas formas que se constituyen en garantías para asegurar el buen funcionamiento de los servicios públicos, impidiendo las decisiones irreflexivas, precipitadas o no estudiadas. A diferencia del Derecho Privado, donde las formalidades son excepción, en Derecho Administrativo son la regla.

\footnotetext{
17 Op. cit. p. 295.

18 Op. cit. p. 296.

19. Núvizz Borıa, Humberto, Breve Tratado de Derecho Administratipo del Perú, 3ra. Edición, Arequipa, Cooperativa Editorial Universitaria, 1971, p. 63.

20 Op. cit. p. 63-69.
} 
c) Voluntad libremente manifestada o determinada. Al igual que los actos privados, los administrativos implican una manifestación de voluntad, aunque calificado por la competencia. Como los actos administrativos no son automática materialización de la ley y requieren que el administrador actúe, se necesita que su voluntad no esté viciada. Ello supone existencia de capacidad (requisito genérico de los actos jurídicos), así como también inexistencia de violencia física o intimidación; pero del mismo modo exige que no haya error en el conocimiento de lo esencial para emitir la «voluntad administrativa».

d) Objeto licito y posible. No debe contrariarse ni perturbarse mediante los actos administrativos el orden público ni los derechos ciudadanos. Tampoco pueden conculcarse las normas jurídicas ni transgredir los principios de la función administrativa.

e) Finalidad enmarcada dentro de las leyes. El fin que persiguen los actos administrativos es la utilidad general, que no puede contrariarse. Se trata, a diferencia del objeto, del fin trascendente de todo acto administrativo, que ha de obedecer ciertos principios de convivencia social.

El acto jurídico que obedezca todos estos requerimientos sencillamente subsistirá y tendrá efectos jurídicos.

\section{Nulidad del Acto Administrativo}

El artículo $43^{\circ}$ del TUO establece que, "Son nulos de pleno derecho los actos administrativos dictados por órgano incompetente; contrarios a la Constitución y a las leyes y los que contengan un imposible jurídico; dictados prescindiendo de las normas esenciales del procedimiento y de la forma prescrita por la ley.»

Una primera constatación que podemos efectuar es sobre la calificación que efectúa el artículo respecto de la calidad de la nulidad del acto administrativo: nulos de pleno derecho.

De acuerdo a lo tratado al analizar la naturaleza y efectos del acto jurídico civil, resultaría redundante tal adjetivación ya que la nulidad supone per se que lo es ipso jure, es decir de pleno derecho, por lo que, en principio, no requeriría que fuera declarada.

Sin embargo, el artículo $44^{\circ}$ del TUO determina que «La nulidad será declarada por la autoridad superior que conozca de la apelación interpuesta por el interesado", lo cual supone una diferencia de tratamiento respecto al Código Civil, que permite lo sea de oficio por el juez siempre y cuando sea manifiesta. En cambio el TUO exige que la parte 
interesada la ponga de manifiesto en el recurso de apelación para que tal nulidad pueda ser declarada por el superior jerárquico.

En efecto, el artículo $109^{\circ}$ del TUO, por excepción, permite la declaración de oficio de la nulidad de las resoluciones administrativas, aun cuando hayan quedado consentidas, siempre que agravien el interés publico. En otros términos, si teóricamente la nulidad del acto no agravia el interés público, aún cuando fuere manifiesta o textual, la autoridad administrativa no estaría en la posibilidad de declarar de oficio dicha nulidad, lo cual indudablemente constituye una deficiencia normativa.

Es más, en el supuesto que el administrado, por alguna razón, no interpone el recurso impugnativo dentro de los quince días hábiles (Arts. $98^{\circ}, 99^{\circ}$ y $100^{\circ}$ concordantes con el Art. $49^{\circ}$ del TUO), el ente administrador podría exigirle teóricamente el cumplimiento de un acto administrativo nulo, ya que al quedar consentida la resolución de primera instancia, se vería impedido de interponer la Acción Contencioso Administrativa prevista en el artículo $148^{\circ}$ de la Constitución, que para su admisibilidad requiere que el acto o la resolución se hayan impugnado en la vía administrativa, agotando los recursos previstos en las leyes respectivas (CPC, Art. $541^{\circ}$, inc. 2 ), en este caso en el TUO.

En este supuesto el administrado aparentemente quedaría en situación de indefensión, ya que no le sería aplicable la prescripción de diez años prevista en el inciso 1 del artículo $2001^{\circ}$ del Código Civil para demandar la nulidad del acto jurídico ya que habría perdido la vía judicial idónea para hacerlo.

Sin embargo, consideramos que la respuesta a este supuesto de injusticia, estaría dada porque no estamos frente a un caso de prescripción sino de caducidad, que conforme al artículo $2003^{\circ}$ del Código Civil no sólo extingue la acción sino también el derecho.

En efecto, dentro de los requisitos de admisibilidad de la Acción Contencioso Administrativa, el Código Procesal Civil contempla entre otros que el acto administrativo haya sido impugnado agotando los recursos previstos en las leyes respectivas, y que dicha acción se interponga dentro de los tres meses de notificada o publicada la resolución final (Art. $541^{\circ}$, incs. 2 y 3 ). Este plazo, sin lugar a dudas, es de caducidad. También debe entenderse que consentir en la resolución sin interponer el recurso impugnativo correspondiente implica la aceptación de su vigencia y la imposibilidad posterior de hacer valer ningún otro recurso porque igualmente habría caducado su derecho a ello.

Este tratamiento tan disímil en el ámbito privado y administrativo tiene como sustento que, mientras que en el primero lo que se discuten son intereses privados, de ahí lo lato del período prescriptorio, en el se- 
gundo se encuentra de por medio la seguridad jurídica de los actos de la Administración Pública. Estos no pueden estar sometidos a un largo periodo de incertidumbre.

Otra diferencia interesante entre el tratamiento que da el Código $\mathrm{Ci}$ vil a la nulidad del acto jurídico respecto del TUO es que, este último de manera expresa considera nulo el acto administrativo "contrarios a la Constitución y a las leyes" lo que doctrinariamente implica que estaríamos frente a un caso de nulidad virtual a la que se adhiere Marcial Rubio, y que tal como lo hemos expresado anteriormente el Código Civil sólo se limita a los casos en que el acto jurídico privado sean contrarios a las leyes que interesan al orden público o a las buenas costumbres, que indudablemente constituye un ámbito más pequeño que el que otorga el TUO a este tipo de nulidad.

\section{Nulidad de oficio}

Tal como lo hemos manifestado anteriormente, la autoridad administrativa sólo puede declarar de oficio la nulidad de resoluciones administrativas, aún cuando hayan quedado consentidas, siempre que agravien el interés público. (TUO, Art. 109º).

En consecuencia, las nulidades contempladas en el artículo $43^{\circ}$ del TUO, por más que sean calificadas redundantemente como de pleno derecho, subsistirán y su cumplimiento podría resultar exigible si el administrado no interpone recurso impugnativo a fin de que sea declarada.

Sólo en los casos en que el acto administrativo agravie el interés público, la autoridad administrativa jerárquicamente superior a la que expidió la resolución, podría anularla de oficio.

Pedro Patrón Faura y Pedro Patrón Bedoya, al tratar sobre este tema manifiestan que "Es claro que en todo interés público se encuentra un interés colectivo; pero el interés colectivo no es por si mismo público; para elevarlo a tal categoría es necesario su inclusión dentro de los fines del Estado. Es el mismo interés colectivo colocado por el Estado entre sus propios intereses, asumiéndolos bajo un régimen de derecho público.» 21

Los mismos autores continúan diciendo «Recordemos que la finalidad de toda la Administración es el Interés Público. Esas necesidades que la iniciativa privada no puede satisfacer, son vitales para toda la co- 
munidad y para cada uno de sus miembros. El Estado no puede tener mas que intereses públicos.»

El Diccionario de Derecho Usual de Guillermo Cabanellas, define interés público como "... La utilidad, conveniencia o bien de los más ante los menos, de la sociedad ante los particulares, del Estado sobre los súbditos ...»22

Finalmente, Miguel Marienhoff, expresa que «La Administración, en el ejercicio de su actividad, no se desenvuelve con libertad absoluta, vale decir con prescindencia de todo ordenamiento jurídico; por el contrario debe desenvolverse con sujeción al ordenamiento jurídico. La actividad de la Administración está, entonces, limitada... . La Administración actúa, pues, secundum legem ...». Más adelante, continúa Marienhoff «Se ha dicho, además, que el principio de la legalidad también le impone a la Administración una especie de regla psicológica: la obligación de tener en cuenta, en su acción, el interés público: Es ésta la finalidad esencial de toda la actividad administrativa. El desconocimiento u olvido de este deber puede viciar el respectivo acto... ${ }^{23}$

Dentro de los fines del Estado, recurriendo a la Constitución, podemos encontrar por ejemplo que, el fin supremo de la sociedad y del Estado es la defensa de la persona humana y el respeto de su dignidad (Art. $1^{2}$ ); la protección especial del niño, el adolescente, la madre y el anciano en situación de abandono (Art. $4^{\circ}$ ); el combate y sanción del tráfico ilícito de drogas (Art. $8^{\mathrm{o}}$ ); el derecho de toda persona a la seguridad social (Art. $10^{\circ}$ ); la libertad de enseñanza (Art. $13^{\circ}$ ); el desarrollo científico y tecnológico del país (Art. $14^{\circ}$ ); que nadie se vea impedido de recibir educación adecuada por razón de su situación económica o de limitaciones mentales o fisicas (Art. $16^{\circ}$ ); la erradicación del analfabetismo (Art. $17^{\circ}$ ); la atención prioritaria del trabajo en sus diversas modalidades y en especial la protección a la madre, al menor de edad, y al impedido que trabajan (Art. $23^{\circ}$ ); la defensa de la soberanía nacional, la plena vigencia de los derechos humanos, la protección de la población de las amenazas contra su seguridad, la promoción del bienestar general que se fundamenta en la justicia y en el desarrollo integral y equilibrado de la Nación, la política de fronteras y la promoción de la integración particularmente latinoamericana (Art. $44^{\circ}$ ).

A diferencia del anterior Reglamento de Normas Generales de Proce-

2.3 Marienhoff, Miguel, Tratado de Derecho Administrativo, Abeledo-Perrot, Buenos Aires, Tomo I, p. 69 y ss. 
dimientos Administrativos, aprobado por Decreto Supremo No 006-SC de 11 de noviembre de 1967 que no lo contemplaba, el artículo $110^{\circ}$ del TUO establece que «La facultad de la Administración Pública para declarar la nulidad de las resoluciones administrativas prescribe a los seis (6) meses, contados a partir de la fecha en que hayan quedado consentidas", lo cual a su vez supone que cumplido dicho plazo la autoridad administrativa no puede ejercitar dicha facultad de oficio, correspondiendo declararla al Poder Judicial en una acción de nulidad que tendría que ser promovida por el ente administrador. Así lo ha ratificado el Tribunal Constitucional en el numeral 33 de los fundamentos y literal b) del fallo de 23 de abril de 1997, recaídos en la causa № 008-96-I/TC (Acción de Inconstitucionalidad del Decreto Legislativo 817 -Régimen Previsional a cargo del Estado-).

Desde otra perspectiva si prescribió la facultad del ente administrador, éste deberá continuar aplicando el acto administrativo nulo en tanto dicha nulidad no sea declarada por el Poder Judicial. Un caso patente que se viene observando en los últimos tiempos es el vinculado con las pensiones de jubilación del Decreto Ley № 20530 («cédula viva»), muchas de las cuales han sido otorgadas con infracción de la citada norma, por lo que son nulas y sin embargo, deben continuar siendo pagadas hasta que la autoridad jurisdiccional la declare, tal como lo han establecido diversas ejecutorias de la Sala de Derecho Constitucional y Social de la Corte Suprema de la República.

Continuando con el supuesto de que el acto administrativo agravie al administrado, éste se encontraría entonces a merced de que la Administración Pública tome la decisión y ejercite la acción de nulidad en el caso de haber prescrito su facultad para hacerlo de oficio.

Ni siquiera el administrado tendría la posibilidad de obligar al ente administrador mediante una Acción de Cumplimiento para que éste promueva la acción judicial de nulidad por cuanto dicha acción de garantía procede contra cualquier autoridad «renuente a acatar una norma legal o un acto administrativo" (Constitución, Art. 200 inc. 6), por cuanto la declaración de oficio de la nulidad de resoluciones administrativas constituye una facultad y no una obligación de la autoridad a tenor de lo previsto por el segundo párrafo del artículo $110^{\circ}$ del TUO.

\section{Conclusiones}

a) Tanto los casos de nulidad previstos para el acto jurídico civil 
como para el administrativo suponen, que de ocurrir, son absolutos, es decir nulos de pleno derecho o ipso jure, por lo cual resulta redundante en el TUO los califique como nulos de pleno derecho.

b) Tratándose del acto jurídico nulo regulado por el Código Civil, no sólo el agraviado puede alegar y en su caso demandar su nulidad. También lo puede hacer cualquiera que tenga interés o incluso el Ministerio Público. Asimismo, puede ser declarada de oficio por el juez cuando resulte manifiesta, todo ello dentro del plazo prescriptorio de diez años que consagra el inciso primero del artículo $200 \mathrm{l}^{\circ}$ del mismo Código. En cambio tratándose de la nulidad del acto jurídico administrativo, pese a ser nulo ipso jure o de pleno derecho, sólo puede ser declarado por la autoridad administrativa si ha sido solicitada en el recurso impugnativo correspondiente.

Si el administrado consiente voluntaria o involuntariamente la resolución administrativa que configura un acto nulo, habrá perdido toda posibilidad de que pueda accionar para tal fin ya que la Acción Contencioso Administrativa sólo procede si se han agotado las instancias administrativas. Estamos frente a plazos de caducidad que importan la pérdida de derecho y no de prescripción que sólo afectan a la acción. Ello en aras de la seguridad jurídica de los actos administrativos.

c) El ente administrador está facultado, es decir no obligado, a declarar de oficio la nulidad de los actos administrativos siempre que agravien el interés público, aun cuando la resolución hubiera quedado consentida y dentro del reducido plazo prescriptorio de seis meses. Transcurrido dicho plazo el ente administrador tendría que solicitar al Poder Judicial la declaración de nulidad. El administrado no tiene medio de obligar a la Administración para que ejercite dicha acción judicial. De otra parte, la Administración Pública queda obligada a respetar y en su caso a aplicar los actos nulos hasta que el poder jurisdiccional lo declare.

d) La evidente desigualdad en que se encuentra el administrado frente a la Administración Pública, respecto del tratamiento que otorga el Código Civil a la nulidad de los actos jurídicos privados, y aun cuando reconocemos la necesidad de la seguridad jurídica de la que deben gozar los actos de la Administración Pública, consideramos que se hace necesaria una revisión del TUO a fin de dotar al administrado de algún medio que le permita, cuando menos, poder obligar al ente administrador a hacer uso de su facultad de anulación de oficio o, en caso de haber transcurrido el plazo para ello, a promover la acción de nulidad ante el ente jurisdiccional. 